2018

\title{
Increasing African American Student Success in Speech- Language Pathology Programs
}

\section{Sarah M. Ginsberg}

Eastern Michigan University, sginsberg@emich.edu

DOI: doi.org/10.30707/TLCSD2.3Ginsberg2

Follow this and additional works at: https://ir.library.illinoisstate.edu/tlcsd

Part of the Other Social and Behavioral Sciences Commons

\section{Recommended Citation}

Ginsberg, Sarah M. (2018) "Increasing African American Student Success in Speech-Language Pathology Programs," Teaching and Learning in Communication Sciences \& Disorders: Vol. 2: Iss. 3, Article 5. DOI: doi.org/10.30707/TLCSD2.3Ginsberg2

Available at: https://ir.library.illinoisstate.edu/tlcsd/vol2/iss3/5

This Scholarship of Teaching and Learning Research is brought to you for free and open access by ISU ReD: Research and eData. It has been accepted for inclusion in Teaching and Learning in Communication Sciences \& Disorders by an authorized editor of ISU ReD: Research and eData. For more information, please contact ISUReD@ilstu.edu. 


\title{
Increasing African American Student Success in Speech-Language Pathology Programs
}

\author{
Abstract \\ At this time just under $8 \%$ of the speech-language pathologists in the United States identify themselves as \\ minorities (ASHA, 2016a) despite the efforts of the American Speech-Language-Hearing Association to \\ increase diversity. African Americans are poorly represented in the field at $3 \%$ of the membership (ASHA, \\ 2016a). In order to identify potential mechanisms for increasing the diversity of the field, 11 African \\ American Speech-Language Pathologists were asked to provide recommendations for improving African \\ American student retention in speech-language pathology undergraduate and graduate educational \\ programs. Participants offered recommendations for how to increase the success rate of African \\ American students in speech-language pathology programs, including providing culturally competent and \\ caring mentorship, co-mentoring opportunities in educational programs, and connections to critical \\ resources.

\section{Keywords} \\ African American, academic resilience, higher education, mentoring, cultural and linguistic diversity

\section{Cover Page Footnote} \\ Minor edits made as suggested. Thank you for the feedback.
}


"So we have a problem; it will be with us for a while; and it behooves us to think hard about what can and should be done." Dr. Glenn C. Loury (2002)

Presently in the United States, 3\% of speech-language pathologists (SLPs) identify themselves as Black or African American (American Speech-Language-HearingAssociation [ASHA], 2016a). Past research has focused on reasons for student groups failing to complete academic programs, such as speech-language pathology programs, by examining deficits including academic under preparedness or financial difficulties (ASHA, 2015; Crosley, Heagney, \& Thomas, 2009; Green, 2006; Stephens, Hamedani, \& Destin, 2014). Despite the efforts of ASHA Office of Multicultural Affairs, such as the Student to Empowered Professional (S.T.E.P.) mentoring program (ASHA, 2017a) and the Minority Student Leadership Program (ASHA, 2017b), research has not yielded significant improvements in the academic success of minority students in speech-language pathology programs. The goal of elevating diversity in the professions to $10 \%$ was set almost 20 years ago and still has not been met (Stewart \& Gonzalez, 2002).

The present study examined mechanisms African American Speech-Language Pathologists (AASLPs) identified as helping them be successful in completing their undergraduate and graduate degrees. Further, the study sought to understand participants' recommendations for improving retention of future African American speech-language pathology students based on their experiences. The use of an academic resilience framework places an emphasis on the processes and experiences of those who have been academically successful despite a general lack of success for those with the same background (Kitano \& Lewis, 2005; Morales \& Trotman, 2004,). In this way, we, academics in communication sciences and disorders (CSD), can examine mechanisms for success instead of failure, in order to potentially replicate the factors and conditions such that the success of others can be increased (Morales, 2008). It is critical to recognize that no one group of students who share similar demographics, such as race, gender, or ethnicity are a homogenous group. However, learning from the lived experiences of a few of the group members, particularly with a range of backgrounds, can help shed light on different insights that might not otherwise be available to non-group members.

The first portion of the study reported the aspects of the educational experiences which were particularly challenging to the 11 AASLPs and the key factors that they felt were critical to their success (Ginsberg, 2018). When asked to identify obstacles that had to be overcome during their speech-language pathology educations, virtually all participants described some form of "microaggressions" from faculty or clinical educators. Microaggressions are "subtle (often unintentional or unconscious) forms of racial discrimination" (Nadal, Wong, Griffin, Davidoff, \& Striken, 2014, p. 461) and can be verbal or nonverbal in nature. Microaggressions are harmful because of their cumulative effect; however, for students they can be particularly damaging, resulting in frustration, discouragement, and feelings of isolation (Nadal et al., 2014; Solorzano, Ceja, \& Yosso, 2001; Sue et al., 2007). Criticisms of the concept of microaggressions include that it is not well supported by evidence, that it can dampen controversial speech, particularly when it is used to foster political correctness, and that it can "perpetuate a victim culture" (Lilienfeld, 2017, p. 140). The inclusion of the construct of microaggressions here does not imply unquestioned support for the validity of concept, but rather it is included because it is a reflection of what many participants described as their lived experiences. Examples of microaggressions that participants noted included being treated as a member of a stereotyped group, feeling isolated due to exclusion 
from study groups, and having their abilities questioned in a manner that was inconsistent with nor explained by their academic performance.

While study participants described frustrations due to what they described as the microaggressions they experienced during their education, the AASLPs in the study also described those factors which they felt were key to their success (Ginsberg, 2018). These factors included receiving mentoring on a professional and "personal level," developing a sense of community through formal or informal groups outside of their academic programs and having a strong sense of selfesteem and determination. For the AASLPs in this study, knowing that mentors cared about them and provided them with affirming messages was very important. Many found comfort in groups of friends who were more accepting of their racial identity outside of the speech-language pathology program, such as campus and service organizations. While none of the study participants attributed their academic success to their personal characteristics explicitly, they often described their resolve or "grit" to be successful and become a professional in the field, no matter what challenges they had to overcome.

\section{Research Question}

As noted above, the first portion of the study was completed in order to understand what factors in the AASLPs education posed challenges and what factors were instrumental to their academic success, reflecting their high degree of success. This portion of the study asked the participants to identify recommendations that they would make to academic programs to increase the persistence and success of African American students in speech-language pathology programs based on their academic experiences. They were also asked how Caucasian faculty could be more effective in supporting African American students, given their overwhelming numbers in the profession.

\section{Method}

This qualitative study used open-ended, semi-structured interviews with 11 AASLPs to gather their recommendations about how African American students could be better supported on their academic journeys to becoming SLPs.

Participants. Volunteers were recruited through digital communication placed in newsletters and announcements posted by the National Black Association for Speech-Language and Hearing (NBASLH) in advance of a national convention. In accordance with the Institutional Review Board (IRB) approved plan, principal investigator contact information was included in electronic communications and participants who identified themselves as being both African American and SLPs were asked to volunteer. Additional snowball sampling, whereby one participant shares information with other potential participants, occurred when volunteers shared study information with their colleagues who in turn contacted the principal investigator to volunteer. Participants included eleven SLPs, two men and nine women, who currently hold the Certificate of Clinical Competence (CCC-SLP) from ASHA (ASHA, 2016b), holding a master's degree in field at a minimum. Participants averaged 11 years of experience, ranging from 1 to 20 years and were between the ages of 26 and 47. Table 1 lists the participant demographic data, including degrees held and types of universities attended.

Table 1 
Participant Demographics

\begin{tabular}{|l|l|l|l|l|l|}
\hline Participant & $\begin{array}{l}\text { Undergraduate } \\
\text { Institution }\end{array}$ & $\begin{array}{l}\text { Graduate } \\
\text { Institution(s) }\end{array}$ & Degree & $\begin{array}{l}\text { Years } \\
\text { Cert. }\end{array}$ & Work Setting \\
\hline Chiron & Public & Public/Public & Ph.D. & 18 & Public University \\
\hline Karen & Public & Public/Public & Ph.D. & 9 & Private University \\
\hline Jeremiah & HBCU public & Public/Public & Ph.D. & 10 & Public University \\
\hline Helen & Private & Public/Private & $\begin{array}{l}\text { Ph.D. } \\
\text { program }\end{array}$ & 20 & Private University \\
\hline Beverly & HBCU public & Public/Public & $\begin{array}{l}\text { Ph.D. } \\
\text { program }\end{array}$ & 12 & Public University \\
\hline Nandi & Private & $\begin{array}{l}\text { HBCU } \\
\text { public/Private }\end{array}$ & CD-SLP & 12 & K-12 Education \\
\hline Katarina & Public & Public/Private & CD-SLP & 12 & Healthcare \\
\hline Kezia & HBCU private & Public & Master's & 8 & Healthcare \\
\hline Rachel & Private & Public & Master's & 12 & Healthcare \\
\hline Michaela & Public & Public & Master's & 1 & Healthcare \\
\hline Joslin & HBCU private & Public & Master's & 10 & K-12 Education \\
\hline
\end{tabular}

Data Collection. All participants were individually interviewed for up to one hour. Interviews were semi-structured, using open-ended questions to ask for recommendations each had for increasing the numbers of African American SLPs (AASLPs) in the future. Each participant was asked what recommendations they would make to improve the higher education experience for African American students in speech-language pathology programs. Six participants were interviewed face-to-face and five were interviewed by phone, in compliance with the IRB protocol. The use of interviews allowed for gaining insights into the individual's perceptions and attitudes (Creswell, 2003) and allowed the participants to recount their experiences and thoughts in rich detail, providing “thick descriptions" (Denzin \& Lincoln, 2003, p. 98).

Data Analysis. All interviews were audio recorded with the participants' permission and transcribed by a professional transcriptionist. Participants chose or were given a pseudonym to protect their identity and any identifying information was similarly altered. Transcriptions were read, with data analyzed first at the sentence level before being coded and compared to each other to consolidate connections and emerging themes (Creswell, 2003). Codes and themes are then connected to begin forming theoretical models (Denzin \& Lincoln, 2003). Member checking was completed with a participant and peer debriefing was completed with a colleague with relevant professional background to verify credibility and authenticity (Creswell, 2003). 


\section{Results}

The participants were asked to identify mechanisms that would be valuable for implementation in higher education speech-language pathology programs to increase the successful graduation rate of African American students. Providing AASLP students with African American mentors was seen as an ideal by some, but not all individuals. Given the relative scarcity of AASLP faculty across the country, participants were also asked how Caucasian educators mentoring African American students could be more effective.

Mentoring. Given the participants' descriptions of the importance of caring mentors who attended to their own well-being, it was not surprising that the AASLPs in this study consistently indicated that effective mentoring of future students was one of the most critical factors for the success of future African American students. Suggestions regarding mentoring fell into three general categories: culturally competent and caring mentoring, co-mentoring, and mentors connecting students to outside resources

Culturally competent, caring mentoring. In discussing Caucasian faculty and clinical educators developing mentoring relationships with African American students effectively, several AASLPs called for an increase in faculty cultural competency. Karen observed that she feels "diversity is a buzz word, but when it comes to actually happening, it is one of those things where we talk about it, but we never talk about how, or really implement change." Joslin suggested that "faculty tap into their own personal prejudices and preconceived ideas about different races or students of different races." Katarina added that graduate students are not "as well trained as they should be" regarding cultural competence. "So we have a kind of double whammy-you don't have the minority staff and we don't have cultural competence there [in Caucasian colleagues] either. You need both" she said. Kezia observed that "it is very hard to teach microaggressions because people don't notice that it happened." She wanted to see competency training focused on helping Caucasian colleagues not only recognize the microaggressions, but also combat them so they could be helpful to colleagues in difficult situations because "we are all in this together."

Rachel advocated that faculty see "the student as a person" and "take the time to know them and see what their strengths and weaknesses are, and their passions." Though it should be acknowledged, as Kezia did, that there is not a one size fits all solution, just because of how students identify themselves. "We are not a homogenous group, so it is a tricky thing...because you want people to feel supported, but you don't want people to feel singled out." She went on to suggest "just don't make assumptions, but really give the students the chance to talk; to make them feel like they are heard. Because that is what we are taught to be with the patients." Joslin added to this the caution about treating a student as a spokesperson for their race

Not singling out an African American student as the "expert" on his/her race by asking specific questions or opinions regarding any topic dealing with black people. Usually if a person feels it is necessary and has something she wants to add to the conversation about "race" she will speak up. She will be more likely to contribute to the conversation if she feels the environment is "safe" to speak--which can be fostered when an authentic rapport has been built among faculty-staff and students of color. 
Jeremiah added that it is important for "White faculty to engage with African American students...I mean to try and understand the challenges that they face. Talk to them." He went on to explain "Black students...need an ally. Someone who is concerned about them and their unique issues."

Mentorship that was caring and personal in addition to being culturally competent was recommended by the participants. Nandi described the "best mentorship happens when you have to build rapport and a trusting relationship." She went on to note that faculty need to find out "what students' needs are" and "what is going to make them feel comfortable coming to your door when they have a problem or a question." Michaela also described the need to establish "trust" with students. "Showing you care" for students was described by Kezia is being an important aspect of effective faculty mentoring. Chiron suggested faculty create an "atmosphere in which students feel comfortable talking about 'life' issues" and not "being afraid to ask questions such as does the student feel like they belong." Joslin described "fostering" a sense that it is "safe" for students to speak through the development of "authentic rapport."

Participants suggested that African American students in speech-language pathology programs might benefit from a more proactive approach to mentoring by focusing on the individual beyond academic performance. Chiron recommended that Caucasian faculty need to "learn to recognize the signs of feelings of isolation." Michaela felt that a stronger sense of "an inclusive welcoming atmosphere to let people know they are just as important as anybody else" needs to be created in our educational programs and that "we have to be open to diversity on all levels. And we have to understand that there is an unspoken beauty in being different." Nandi also suggested that faculty mentors can help decrease the sense of isolation by creating opportunities for student to student connections in the department and their courses by "matching students up so they have buddies within the department- team building, on a student level, so that they get to know people and they are not just isolated."

Another element that participants focused on was the need for mentors to provide encouragement. Helen suggested that affirmations might be necessary to overcome the frustrations that have come from previous challenges and microaggressions that African American students have experienced. Specifically, she stated the following

African-American students sometimes come in with a feeling of inferiority- the stereotype threats...they have heard overtime and I think it is learning how--I don't think it is difficult-learning how to affirm them in a way and let them know by how you interact with them that they are very much capable and they can do this.

Karen noted that mentors can provide "encouragement" for students who might not be able to see their own potential as they struggle with various aspects of their academic progress "sometimes people who give you a vision and kind of tell you who you could become" can help students keep going. Katarina said that she felt that African American students needed to have "someone to say, 'You may not have the experience, but you have the potential. It is something you can be taught and you can grasp it. I feel like you are worth that investment.",

"Co-mentoring." Participants noted that the lack of visibility of AASLPs during their own education was disheartening. Beverly noted "students of color like to see other people that look like them." In the absence of available African American faculty in speech-language pathology 
programs, helping students connect to other African American faculty from other campuses or related professionals can be supportive. Karen suggested "encouraging them to have more than one mentor because I feel like each mentor you take something different from them." Chiron wished that he had been able to interact with African American professionals and receive mentoring from them while in school. As a university professor, he reported that now hears from his African American students that seeing African American faculty is reassuring that "just knowing that you are here helps." In an effort to provide what he referred to as "co-mentoring" to African American students beyond his campus, he volunteers in the ASHA S.T.E.P. program which "facilitates the continued recruitment and retention of racial/ethnic minority students" (ASHA, 2017a). His experience with a local mentor of S.T.E.P. participant revealed the need for discourse regarding the value of same-race mentoring.

I got an email from a faculty who is at the institution where one of my mentees was. And he introduced himself and he was really nice about it but the tone of the email was, "Why does he need you as a mentor when I am here?" And this was a White colleague. And I was really surprised to receive this email, but I was also happy because I think there are other White faculty that feel that way like, "I am a good mentor. Why does he need another mentor? I have a good relationship with him." So I was able to start up this dialogue with him about that this isn't to step over you or anything like that; in fact, I encourage them to find faculty there, but also trying to explain to him about that there are some things that he won't understand about that experience... because there is no way I could understand what it is like to be a White student. So it opened a really good dialogue. And we probably emailed back and forth for about a week and at the end, he thanked me because he didn't think about it that way.

Those interviewed suggested that even in programs where there are no minority faculty or clinical educators, there are ways to increase the visibility of diversity in our field, which would be encouraging. Chiron suggested that we can create visibility and mentoring opportunities for African American students beyond what is available within the faculty. He commented that "we all have externship sites, we all have a guest lecture or adjunct or something like that, that reaching out to our community members." He indicated that it might be valuable to "connect Black students with other Black faculty on campus or Black professional SLPs in the community." Similarly, Michaela recommended bringing "minority individuals who are in the field to be 'guest speakers'." Beverly observed that "sometimes people forget just how important that is to have... somebody who looks like them that they can go and talk to."

Connecting to outside resources. The value of getting students connected by their mentors to resources that existed beyond the local campus was commented on by many of those interviewed. Chiron, who felt as though he had found family upon arrival at his first NBASLH convention suggested the faculty should "send students to NBASLH for the purpose of connecting with Black faculty, professionals, and students." Karen and Jeremiah also suggested connecting students to NBASLH, as well as the ASHA S.T.E.P. program. Jeremiah added that "many students at PWIs [predominantly white institutions] have no knowledge of these tremendous resources." He went on to note that by participating in NBASLH, "they have an opportunity to connect with mentors and peers who are dealing with or have dealt with some of the same challenges." Karen also 
recommended "encouraging them to go to conferences like ASHA and NBASLH" and to take advantage of "student leadership programs."

Karen noted that mentors who can help students "navigate" the systems of higher education can be very helpful when students aren't sure what their next step should be or how to achieve their goals. She also advocated for mentors helping students find opportunities to take advantage of that would be valuable to their learning, such as going to "work at a camp with developmental disabilities" or "go shadow someone who is a speech language pathologist." Katarina felt that AASLP students might not take advantage of opportunities because of both misinformation and a lack of information. She recommended that there be more "outreach" from clinical and academic mentors to let students know what is available to them, sharing with them "Hey, these organizations are out here, you don't have to be bilingual [for example], you really should apply." Jeremiah suggested "Perhaps inviting them to help with a project" which would give them extended opportunities to learn and make connections with peers and faculty.

\section{Discussion}

Recommendations. The recommendations of the 11 AASLPs were focused on how to support African American students in speech-language pathology undergraduate and graduate programs in order that they persist in their programs to become AASLPs. Their insights were tied to their own experiences of having caring and supportive mentors, who viewed them as an individual, took them "under their wing," and helped them navigate the unchartered waters of higher education and speech-language pathology. They also identified the value of having culturally competent mentors who were able to connect students to outside resources, such as professional programs, and of having African American "co-mentors" who could provide additional mentoring and support as the students move toward degree completion.

Culturally competent, caring, mentoring. According to ASHA (ASHA, 2016b), all certified clinically competent speech-language pathologists (CCC-SLP) are expected to be culturally competent. Standard V-B: Interaction and Personal Qualities notes that SLPs should be able to "communicate effectively, recognizing the needs, values, preferred mode of communication, and cultural/linguistic background of the client/patient, family, caregivers, and relevant others" (ASHA, 2016b, "Interaction and Personal Qualities") The expectations of being a culturally competent clinician include the ability to "appreciate cultural patterns and individual variation" (ASHA, 2017c, "Developing Cultural Competence") and to "engage in cultural self-scrutiny to assess cultural biases and improve self-awareness" (ASHA, 2017c, "Developing Cultural Competence"). Faculty in speech-language pathology programs should be particularly familiar with the concept of cultural competence as they must not only be culturally competent as clinicians, but must also teach it to their students. The recommendation from a number of AASLPs in this study would suggest that in the process of preparing students, educators need to evaluate their own "personal prejudices and preconceived ideas about different races," as Joslin noted, in order to be able to effectively teach, mentor, and instill in others the capability of broad cultural respect and aptitude. Programs that support faculty in the process of assessing their own evaluation of their cultural competence (ASHA, 2017d) have the potential to create more capable clinicians in their program and to be more effective in preparing all speech-language pathology students for the field. The recommendations for faculty in speech-language pathology programs to see the student as more than a spokesperson for their race and see "the student as a person" is consistent with 
providing culturally competent mentoring. In order to effectively educate culturally and linguistically diverse students, we need a paradigm shift away from tolerance, which connotes acceptance of something not approved of or understood, toward cultural appreciation, which suggests seeing the value inherent in those who are different (Cross, Bazron, Dennis, \& Isaacs, 1989; Kimmons, 2017).

An alternative way to address understanding of cultural differences is to teach cultural humility (Foronda, Reinholdt, \& Ousman, 2016; Guskin, 2015; Tervalon \& Murray-Garcia, 1997). Cultural humility means recognizing another individual's culture as being valid and not less than one's own. In this concept, one recognizes the human tendency to judge different cultures and ascribe lower value on those aspects of the culture, such as intellect and dignity. Attaining a sense of cultural humility means questioning the "primacy" of your own culture and entering into new cultural contexts in a "learning mode" (Bennett, 2015, p. 163). Being in learning mode is consistent with the ideals and skills of SLPs as it requires attending carefully to communication, both verbal and nonverbal. It also requires attributes of openness to interactions with individuals from different cultures and developing self-awareness and self-reflection regarding one's own views and beliefs (Foronda et al., 2016). In the context of providing care for others, Tervalon and Murray-Garcia (1997) popularized the notion of health care practitioners with cultural humility to "develop and maintain mutually respectful and dynamic partnerships with communities" (p. 118). The term humbleness embodies professionals who work to achieve cultural humility (Foronda et al., 2016).

Though there has been limited research regarding the value of effective mentoring specifically for African American students in PWIs, we do know that effective mentors and role-models can be significant factors for improving the retention of African American students (Brittian, Sy, \& Stokes, 2009; Ginsberg, 2018). New models of mentoring call for a fresh view of mentoring that eschews the interpretation of mentors as the holder of all knowledge and the mentees as the recipients (Ginsberg, Friberg, \& Visconti, 2012; Mullen, 2016). New mentoring models can provide for opportunities for learning to be bidirectional and for acknowledgements of issues around authority, power, privilege and exclusion that can be experienced by any marginalized group member (Mullen, 2016). Mentoring relationships should be characterized by opportunities for the mentor to provide to the mentee or protégé the opportunities to not only solidify their knowledge or application of content knowledge, but to provide them with knowledge about "how to cope with challenges that lie ahead" and to "provide moral support" (Morales, 2010, p.388-89). Taking a more comprehensive view of the mentoring relationship can support the mentees' growth in terms of social and emotional professional development as well (Mullen, 2016). This might suggest that mentors need to be watchful for as Chiron described "signs of feelings of isolation" and addressing support needs beyond just course content. As study participants emphasized, mentors need to demonstrate to their protégés that they are an "ally," that they will encourage and affirm them, and that they are there to be "trusted" in times of challenge.

“Co-mentoring." For some participants, the lack of visible AASLP for their African American students was problematic. They noted that they felt students in speech-language pathology programs would do better if they were able to have role models were the same race as the students. Other participants felt that the quality of the mentoring relationship was more critical than a racial match (Ginsberg, 2018; Mullen, 2016). Unfortunately, as participants acknowledged and the literature has noted, same-race mentoring is not always available or feasible within any given academic setting (Dolan, 2007; Stanley \& Lincoln, 2005). In response to the shortage of African 
American faculty members, participants suggested that academic programs find opportunities for AASLP students to receive "co-mentoring" from other sources, such as through the ASHA S.T.E.P. program (ASHA, 2017a), NBASLH, or having AASLPs from the community participate in classes through guest lectures. Formal and informal mentoring programs can bring students new perspectives and new opportunities to speak openly about difficult situations (Brittian et al., 2009) and have been demonstrated to be highly effective in increasing student retention and satisfaction (Mullen, 2016). Having more than one mentor is more feasible now than ever with the availability of technology, such as the use of videoconferencing, which can make it easier for a smaller group of key faculty to have contact with a wide group of students looking for support, independent of geography. Chiron's active mentoring of students in the S.T.E.P. program from around the country is an example of the opportunity for AASLP students to have co-mentors and to "take something different from each" mentor who is available to them. Caucasian faculty need to consider the possibility of seeking out African American colleagues in other fields or beyond the university in order to provide students with a variety of mentors, some of whom "look like them" and with whom they can develop additional mentoring relationships.

Connecting to outside resources. Participants in this study suggested that speech-language pathology faculty need to connect students to resources that exist outside of the parameters of the academic program or outside of the standard program offerings. The AASLPs interviewed felt that students needed to be informed about summer volunteering and conference attendance opportunities. In their view, students sometimes need to be pointed in the direction of the resources that are available to them such that they can take advantage of them to benefit their learning and career goals. Morales (2010) identified this phenomenon as "mentors as suppliers of inside information" (p. 394). Additionally, it has previously been noted that underserved students, including students of color and first-generation college students, need more support to learn how to navigate higher education institutions (Green, 2006). The provision of this information can be particularly valuable for students who are unfamiliar with higher education in general, with a specific profession, or with a new organizational culture. The insider information coming from the mentors can help students find resources that they might not otherwise know to look for, such as NBASLH.

Conclusion. The recommendations that the 11 AASLPs, who were successful in completing at least Master's degrees in speech-language pathology shared might help undergraduate and graduate speech-language pathology programs with implementation of better practices. Adopting more effective mentoring and support programs could improve the outcomes of future African American students as well as contribute to a rise in the diversity of the field. We all need to be culturally competent as educators and clinicians. This means being open to hearing the perspectives of our colleagues and of our students who have cultural or linguistic differences. It also requires that we move beyond competence toward an open appreciation of diversity. In order to support students who are not part of the Caucasian, female majority, it is critical that we understand each individual's unique needs. We need to be mindful of how students can benefit from trusting mentoring relationships with faculty within and outside of academic programs. Further, we all need to educate ourselves regarding what resources are available that might be valuable to students who are in need of our support. We are the insiders who can give students the critical information that will help them "navigate" and can be the difference between success and 
failure. It is incumbent upon us all as educators to identify valuable resources for all of our students and help them connect to those individuals, groups, or programs.

In summary, higher education program need to reflect on ways in which they can provide better support for culturally and linguistically diverse students. The assumption that students of color, or any other minority, do not succeed because of their deficiencies is a flawed and fundamentally ineffective approach to improving the diversity of our professions. Table 2 summarizes key elements that CSD programs should consider in becoming more effective educating a diverse student body.

Table 2

Education Recommendations
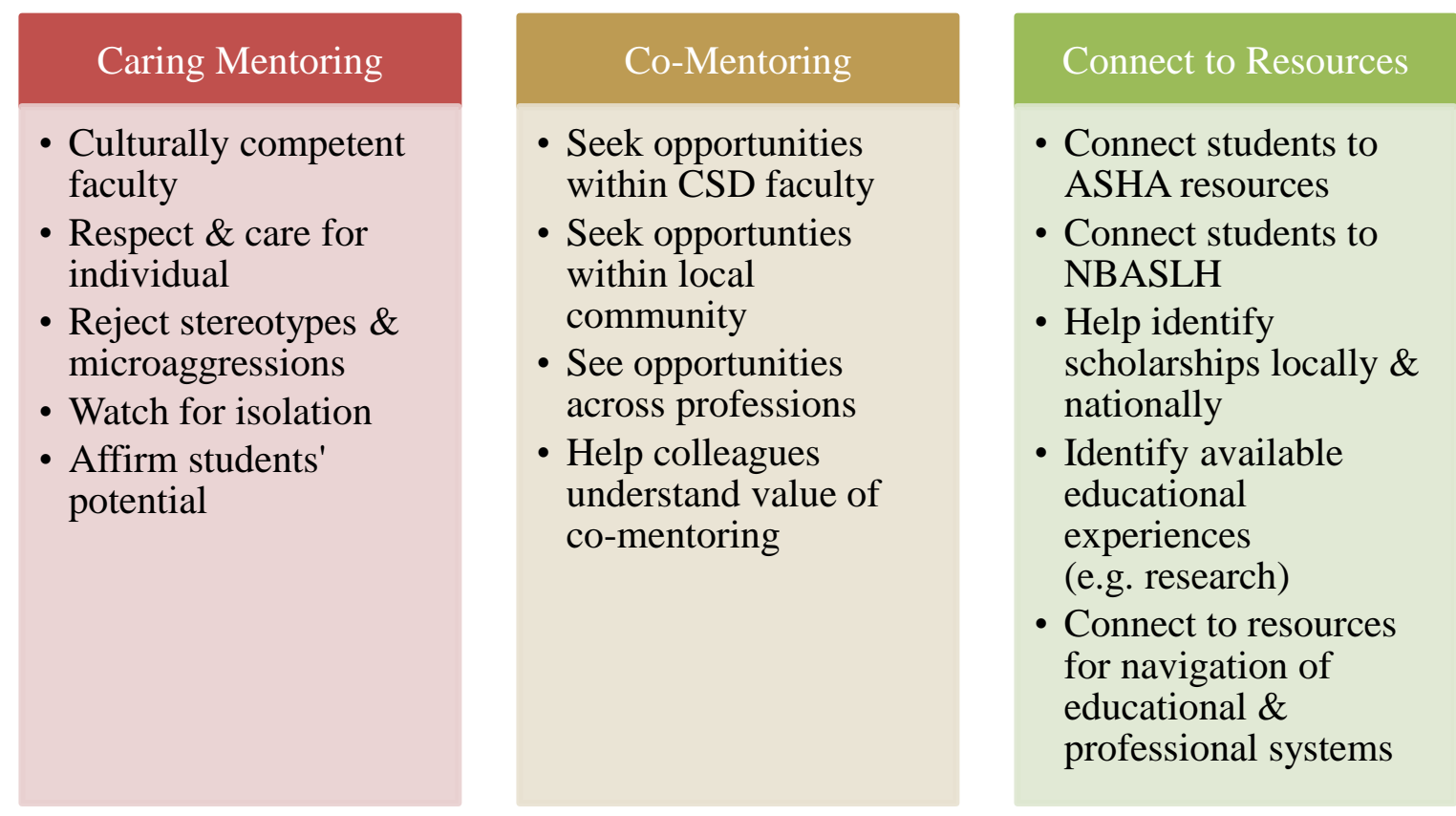

If we listen to the informed opinions and recommendations of those who have lived the experience, we can improve the educational experience for all of our students.

Limitations. The focus of this portion of the study was on the role that faculty and clinical educators could play in improving the outcomes for students enrolled in undergraduate and graduate speech-language pathology programs. Therefore, the discussion was limited to recommendations for higher education programs and did not include suggestions for how to increase interest of our field amongst African American middle school and high school students. This is a topic that has significant potential to improve the rates of African American students who consider or declare speech-language pathology once they enroll in college. This study was limited in that only 11 AASLPs' perspectives were represented. While they represented a diverse range of ages, experiences, and backgrounds, we need to be particularly cautious about assumptions regarding race and homogeneity, being aware that there is no "one size fits all" for students in any type of group, including African Americans. Most participants were members of NBASLH and attended an NBASLH convention. In addition to being members of NBASLH, many had completed or were in the process of completing terminal degrees. These two factors further 
limiting the generalizability of the results. Future directions for related studies would include examining the academic success of a wide array of culturally and linguistically diverse students in speech-language pathology programs. As greater attention has started to be focused on the mental health of college students, including feelings of isolation, further investigation into the emotional health of students enrolled in speech-language pathology programs could be warranted. Additionally, professional education to improve the professional practices with diverse cultures might also be explored through the use of continuing education based on the cultural humility model.

Students are not homogenous, any more than race labels are. We cannot make assumptions about our students' strengths, needs, or goals based on their race. By respecting each student as an individual and supporting them in a non-judgmental way, we can begin to engage in a dialogue with students from diverse backgrounds such that we can help increase their academic resiliency. It is only by engaging in the sometime awkward and difficult dialogues with each other and with our students that we have any hope of improving the diversity of the field of speech-language pathology. It is critical that we continue the self-exploration and improvement of practices that cultural competence requires if we are to move the needle of diversity from near the bottom of the gauge.

\section{References}

American Speech-Language-Hearing Association. (2015). Minority student recruitment, Retention and career transition practices: A Review of the literature. Retrieved from http://www.asha.org/practice/multicultural/recruit/litreview/

American Speech-Language-Hearing Association. (2016a). Highlights and Trends: ASHA Counts for Year End 2016. Retrieved from http://www.asha.org/uploadedFiles/2016-MemberCounts.pdf

American Speech-Language-Hearing Association. (2016b). 2014 Standards and Implementation Procedures for the Certificate of Clinical Competence in Speech-Language Pathology. Retrieved from https://www.asha.org/certification/2014-speech-language-pathologycertification-standards/

American Speech-Language-Hearing Association. (2017a). About S.T.E.P. Retrieved from http://www.asha.org/Students/mentoring/step/AboutSTEP/

American Speech-Language-Hearing Association. (2017b). Minority Student Leadership Program (MSLP). Retrieved from http://www.asha.org/students/mslp-award/

American Speech-Language-Hearing Association. (2017c). Cultural Competence. Retrieved from http://www.asha.org/PRPSpecificTopic.aspx?folderid=8589935230\&section=Key_Issues

American Speech-Language-Hearing Association. (2017d). Self-Assessment for Cultural Competence. Retrieved from http://www.asha.org/practice/multicultural/self/

Brittian, A. S., Sy, S. R., \& Stokes, J. E. (2009). Mentoring: Implications for African American college students. The Western Journal of Black Studies, 33(2), 87-97.

Creswell, J. N. (2003). Research Design: Qualitative, Quantitative, and Mixed Methods Approaches (2 ed.). Thousand Oaks, CA: Sage.

Crosley, G., Heagney, M., \& Thomas, L. (2009). Improving student retention in higher education. Australian Universities' Review, 51(2), 9-18. 
Cross, T., Bazron, B., Dennis, K., \& Isaacs, M. (1989). Towards a culturally competent system of care, Volume I. Washington, DC: CASSP Technical Assistance Center, Georgetown University Child Development Center, CASSP Technical Assistance Center. https://spu.edu/ /media/academics/school-of-

education/Cultural\%20Diversity/Towards\%20a\%20Culturally\%20Competent\%20System $\% 20$ of\%20Care\%20Abridged.ashx

Denzin, N. K., \& Lincoln, Y. S. (2003). Collecting and interpreting qualitative materials. Thousand Oaks, CA: Sage.

Dolan, T. G. (2007). Is cross-race mentoring a negative? The Education Digest, 73(4), 26-30. Retrieved http://ezproxy.emich.edu/login?url=https://search.proquest.com/docview/218184385?acc ountid $=10650$

Foronda, C., Baptiste, D. L., Reinholdt, M. M., Ousman, K. (2016). Cultural humility: A concept analysis. Journal of Transcultural Nursing, 27(3), 210-217.

Ginsberg, S. M. (2018). Increasing African American student success in speech-language pathology programs. Teaching and Learning in Communication Sciences \& Disorders, 2(3). Retrieved from www.tlcsdjournal.com

Ginsberg, S. M., Friberg, J. C., \& Visconti, C. F. (2012). Scholarship of Teaching and Learning in Speech-Language Pathology and Audiology: Evidence-Based Education. San Diego, CA: Plural Publishing.

Green, D. (2006). Historically underserved students: What we know, what we still need to know. New Directions for Community Colleges, 135(Fall), 21-28. doi: 10.1002/cc

Guskin, A. (2015). Cultural Humility. In J. Bennet (Ed.) The SAGE Encyclopedia of Intercultural Competence (pp. 163-164). Thousand Oaks, CA: Sage.

Kimmons, M. (2017). "Tolerance" is not enough. The ASHA Leader, 22(8), 8-9.

Kitano, M. K., \& Lewis, R. B. (2005). Resilience and coping: implications for gifted children and youth at risk. Roeper Review, 27(4), 200-205.

Lilienfeld, S. O. (2017). Microagressions: Strong claims, inadequate evidence. Perspectives on Psychological Science 12(1), 138-169.

Loury, G. C. (2002). The Anatomy of Racial Inequality. Cambridge, MA: Harvard University Press.

Morales, E. E. (2008). The resilient mind: The psychology of academic resilience. The Educational Forum, 72(2), 152-167.

Morales, E. E. (2010). Legitimizing hope: An exploration of effective mentoring for Dominican American male college students. Journal of College Student Retention, 11(3), 385-406.

Morales, E. E., \& Trotman, F. K. (2004). Promoting academic resilience in multicultural America: Factors affecting student success. New York, NY: Peter Lang.

Mullen, C. A. (2016). Alternative mentoring types. Kappa Delta Pi Record, 52(3), 132-136, doi: 10.1080/00228958.2016.1191901

Nadal, K. L., Wong, Y., Griffin, K. E., Davidoff, K., \& Striken, J. (2014). The adverse impact of racial microaggressions on college students' self-esteem. Journal of College Student Development, 55(5), 461-474.

Solorzano, D., Ceja, M., \& Yosso, T. (2001). Critical race theory, racial microaggressions, and campus racial climate: The experiences of African American college students. The Journal of Negro Education, 69(1/2), 60-73. 
Stanley, C. A., \& Lincoln, Y. S. (2005). Cross-race faculty mentoring. Change, 37(2), 44-50.

Stephens, N. M., Hamedani, M. G., \& Destin, M. (2014). Closing the social-class achievement gap: A difference-education intervention improves first-generation students' academic performance and all students' college transition. Psychological Science, 25(4), 943-953.

Sue, D. W., Capodilupo, C. M., Torino, G. C., Bucceri, J. M., Holder, A. M. B., Nadal, K. L., \& Esquilin, M. (2007). Racial microaggressions in everyday life: Implications for clinical practice. American Psychologist, 62(4), 271-286.

Tervalon, M. \& Murray-Garcia, J. (1998). Cultural humility versus cultural competence: A crucial distinction in defining physician training outcomes in multicultural education. Journal of Health Care for the Poor and Underserved, 9,(2), 117-125. 